\title{
Expropriation risk and technology is
}

\author{
Marcus M. Opp* \\ Haas School of Business, University of California at Berkeley, 545 Student Services Building \#1900, CA 94720-1900, United States
}

\section{A R T I C L E I N F O}

\section{Article history:}

Received 25 October 2010

Received in revised form

28 February 2011

Accepted 14 March 2011

Available online 31 August 2011

\section{JEL classification:}

D86

D23

F21

F23

F52

G38

\section{Keywords:}

Expropriation risk

Foreign direct investment

Dynamic contracting

Property rights

Self-enforcing contracts

Principal-agent models

Political risk

\begin{abstract}
A B S T R A C T
This paper develops a unified framework to analyze the dynamics of firm investment in countries with poor legal enforcement. The firm's technology edge over the government generates endogenous property rights. Industry variation in the technology gap predicts a sectoral pecking-order of expropriations. Long-run investment distortions may be Pareto superior relative to persistent investment at the static optimum. The dynamics of investment and transfers depend on whether incentives (backloading) or efficiency (frontloading) concerns dominate at the initial division of surplus. An increase in government efficiency may reduce its welfare. The model provides a technology-driven rationale for the widespread use of conglomerate structures in emerging market countries.
\end{abstract}

(c) 2011 Elsevier B.V. All rights reserved.

\footnotetext{
This paper is based on a portion of my thesis at the University of Chicago, Graduate School of Business. I thank my advisors Doug Diamond, Milton Harris, Raghu Rajan and Morten Sorensen for many insightful comments and their extensive time commitment. My paper has greatly benefited from discussions with Mike Fishman, William Fuchs, Martin Hellwig, George Mailath, Roger Myerson and Harald Uhlig. I appreciate valuable feedback from Gary Becker, Johannes Bruder, Thomas Chaney, Peter DeMarzo, Pedro Gete, Anil Kashyap, Marlena Lee, Atif Mian, Christian Opp, Christine Parlour, Alessandro Pavan, Marcin Peski, Bilge Yilmaz, Luigi Zingales and an anonymous referee as well as seminar participants at Berkeley, Columbia, Duke, Harvard, Max Planck Institute Bonn, MIT, Northwestern, NYU, Stanford, UCLA, University of Chicago (GSB, Econ) and University of Pennsylvania (Wharton, Econ). Research support from the Katherine Dusak Miller Ph.D. Fellowship in Finance, the John Leusner Fellowship, as well as the ERP Fellowship are gratefully acknowledged. Any opinions expressed herein are the author's.

* Tel.: +1 510643 0658; fax: +15106431420.

E-mail address: mopp@haas.berkeley.edu
}

\section{Introduction}

"The Government can promise you whatever it wants - it is not binding".

(Bernard Mommer, Venezuela's deputy oil minister, 2006)

In spring 2007, Venezuela took over the oil projects of ConocoPhilips, who wrote down $\$ 4.5 \mathrm{bn}$. At the same time, foreign oil groups led by Eni of Italy are facing a clash with the government of Kazakhstan over the original contract terms for the development of the Kashagan field in the Caspian Sea. Almost provocatively, Kazakhstan's parliament passed a law to allow the government to cancel or change retroactively contracts perceived to harm the national economic interest. If a government breaches a contract—often officially justified by allegations such as 
tax fraud or environmental violations - the affected party cannot rely on an external punishment mechanism to enforce the written contract. ${ }^{1}$ Due to the mere threat of expropriation, firms may not pursue otherwise profitable investment opportunities ex ante. These investment distortions are difficult to measure, but represent a large fraction of the economic cost of expropriation risk.

This paper develops a dynamic hold-up framework with two-sided lack of commitment to analyze the dynamics and feasibility of firm investment in countries with a poor legal system. Each period, the government is able to seize all output and capital after firm investment is sunk. Its short-run incentive to expropriate is exacerbated by higher discounting relative to the firm. The firm may leave the country at any point in time. Within a dynamic game, mutually beneficial agreements between the firm and the government may be sustained through the threat of autarky. This threat is more effective the lower the technological capability of the government to take over the project. Intuitively, property rights are safer if the firm is better at operating the project. The security of property rights is also sector-dependent as the technology gap between firms and the government's bureaucrats varies across sectors. While low efficiency of the government makes ex ante firm investment more likely, it also reduces its threat point to extract cash flows from the firm. ${ }^{2}$ For intermediate ability of the government, the firm rationally responds to this threat by reducing the size of investment and thus surplus. If the government's ability is sufficiently high, firm investment is no longer sustainable and the project must be operated with the government's secondbest technology. As a result, the government's equilibrium cash flows are non-monotonic in its relative ability.

Conditional on the feasibility of firm investment, the paper characterizes the dynamics (loading) of efficient selfenforcing contracts. Any efficient self-enforcing contract converges to the same stationary allocation. Thus, while there are a continuum of possible contracts, the long-run allocation of the entire efficient set is uniquely determined. Investment and tax payments are backloaded, i.e., increasing over time, if the firm value is initially higher than in the unique stationary allocation. This is more likely to occur when firm bargaining power is high or the initial capital stock of the project is low. Frontloading refers to the opposite case when the government initially obtains larger payments than in the steady state. These dynamics are driven by the relative magnitude of two competing forces: "efficiency" and "incentives." Due to relative impatience, it is efficient to exploit trading gains across time to provide early, frontloaded payments to the government. On the other hand, backloaded transfers provide incentives for multiple periods by acting as collateral. In the unique steady state, these forces offset each other. The marginal value from trading across time is equal to the marginal product of

\footnotetext{
${ }^{1}$ For example, Russia's takeover of the Sakhalin-2 oil and gas project managed by Shell in 2006 was officially attributed to environmental concerns.

${ }^{2}$ Here, the threat point refers to the attractiveness of the government's outside option which is determined by its autarky production technology.
}

capital. Within a dynamic model, relative impatience gives rise to an additional source of surplus that causes efficient stationary investment to be below the static optimum.

An extension of this benchmark model predicts an industry pecking-order of expropriations. The peckingorder is determined by the technology intensity and the depreciation rate of capital for that sector. Expropriation and privatization cycles adhere to a "Last-In-First-Out" principle. In the model, expropriations occur on the equilibrium path through discount rate shocks to the government. These shocks can be interpreted as regime changes or liquidity shocks.

The model provides a technology-driven rationale for cross-country differences in industrial organization. If firms in sectors with different technology levels coordinate on joint punishment, their effective threat point becomes stronger. The sustainability of such a linkage equilibrium is more likely when formal ties between sectors are prevalent, such as with conglomerate structures. This provides a rationale for firms to engage in non-horizontal integration. Moreover, I discuss the importance for vertical integration in the oil industry. This industry is characterized by a costly exploration phase and an ex post profitable extraction phase. Vertical integration of exploration and extraction is a means to relax the incentive problem of the government. The productivity advantage in the extraction phase secures the required surplus for the oil firm to recover the cost of the potentially unsuccessful exploration phase.

There is anecdotal support for my model. In Bolivia, the announced expropriation of the gas sector upon President Evo Morales' election victory had to be abandoned in 2006 due to lack of local expertise. ${ }^{3}$ Observable features of contracts with sovereign countries show the empirical relevance of frontloading and backloading. I provide anecdotal evidence for select investments of multinational automobile firms in Eastern Europe. Moreover, I analyze the features of production sharing agreements in the natural resources sector. ${ }^{4}$ Kobrin's (1980) comprehensive collection of expropriation acts in emerging market countries lists 563 acts between 1960 and 1979. Consistent with the predictions of my model, Kobrin finds that firms in less technology-intensive sectors (such as extraction or utilities), where the private sector's technological advantage is presumably smaller, face higher expropriation risk than manufacturing or trade firms. Using the same data set, Li (2009) shows that expropriations are positively related to high government turnover. Political economy theory suggests that higher government turnover results in an effective reduction of the discount factor (see Aguiar, Amador, and Gopinath, 2009; Amador, 2004), an event that can trigger expropriation in my model.

\footnotetext{
${ }^{3}$ In general, there is strong empirical support that nationalized companies operate less efficiently due to insufficient technological acumen, not just in the oil and gas sector. A World Bank study by Kikeri, Nellis, and Shirley (1992) reveals how production efficiency increases significantly after privatization of state-owned enterprises Bridgman, Gomes, and Teixeira (2011) show that (the threat of) competition sharply increases the productivity of state-owned firms.

4 These arrangements represent the most common contract form between multinational oil companies and emerging market countries (see Bindemann, 1999).
} 
While the focus of this paper is mainly applied, it has broader implications for the general class of principal agent models with heterogeneous discounting by highlighting the tension between providing incentives via backloading (see Ray, 2002) and efficiency via frontloading (see Lehrer and Pauzner, 1999). With heterogeneous discounting, overall welfare assessments cannot be solely made on the basis of investment efficiency, but must take the timing of cash flows into account. It may be optimal to induce the agent to exert effort below the static optimum.

My paper is organized as follows. Section 1.1 provides a summary of the related literature. Section 2 presents the economic setup of my model. The main analysis is presented in Section 3. This section derives conditions for sustainable firm investment and describes the short-run and long-run properties of efficient self-enforcing contracts. Section 4 discusses applications of my model and provides empirical evidence. Section 5 concludes.

\subsection{Literature}

This paper is related to many strands of the economic literature. Consistent with historical evidence documented by Rajan and Zingales (2003), I develop a theory of endogenous property rights through the lens of technology: Rajan and Zingales show that the evolution of property rights is often directly connected to productivity gains in managing private assets. These productivity gains can be interpreted as changes in the relative efficiency of government technology. Thus, in contrast to the "law and finance" channel (La Porta, Lopez-de-Silanes, Shleifer, and Vishny, 1998) and the "institution" channel (Acemoglu, Johnson, and Robinson, 2001) my paper highlights a third, potentially complementary, "technology" channel.

Although the focus of my paper lies on the expropriation of real assets, for which technology is key, the literature on sovereign debt is fundamentally connected to the findings of my paper. Most importantly, Bulow and Rogoff (1989b) find that the loss of "reputation for repayment" is not enough to induce the borrower to repay. ${ }^{5}$ Hence, additional sanctions such as entire exclusion from financial markets, i.e., borrowing and lending (Eaton and Gersovitz, 1981), or direct trade sanctions (Bulow and Rogoff, 1989a) are needed to sustain sovereign debt. In my setup, the productivity advantage of the firm provides it with an effective sanction mechanism. The maximum feasible up-front payment to the government is determined by the technology-dependent break-even condition of the firm. This generates an endogenous borrowing constraint of the government.

From a modeling standpoint, my paper extends the framework of Thomas and Worrall (1994) by adding heterogeneous discounting, autarky production (technology), and expropriations on the equilibrium path. ${ }^{6}$ Similar to Kovrijnykh (2009), non-monotonic comparative statics

\footnotetext{
${ }^{5}$ See Hellwig and Lorenzoni (2009) as well as Amador (2004) for some qualifications of this result.

${ }^{6}$ Albuquerque and Hopenhayn (2004) generalize Thomas and Worrall (1994) by allowing for a general outside option and incorporating Markov revenue shocks. In contrast to my model, the principal is fully committed to the contract, there is no heterogeneous discounting,
}

of welfare with regards to outside options are generated by (binding) participation constraints. ${ }^{7}$ My paper is also related to a sequence of papers by Acemoglu, Golosov, and Tsyvinski $(2008,2010)$ who study a political economy setup in which an impatient government without commitment can only be disciplined via elections. Since the authors only characterize the equilibrium, which gives maximum utility to the citizens, the government's payoff is necessarily backloaded until the steady state with investment distortions is reached. Long-run investment distortions are also present in the sovereign debt model of Aguiar, Amador, and Gopinath (2009).

Finally, I discuss the connections to the literature on corporate finance. In Hart and Moore (1994) an entrepreneur seeks financing from an outside creditor, but cannot commit not to withdraw his human capital from the project. The model is reverse compared to my setup because in Hart and Moore (1994), the firm is the agent, not the principal. The liquidation technology of the creditors is analogous to the autarky technology in my paper. Due to the reverse nature of the problem, investment is more likely to take place if the liquidation technology is better. The papers differ fundamentally with regards to the enforceability of property rights. Hart and Moore allow for the enforceable transfer of control rights to the creditor upon the debtor's default. In my setup, the effective control right over the project always rests with the government and cannot be credibly transferred. DeMarzo and Fishman (2007) present a dynamic capital structure model in which a relatively impatient entrepreneur, the agent, can secretly divert cash flows. In contrast to my paper, the principal is able to commit to a contract and output is assumed to be exogenous. DeMarzo, Fishman, He, and Wang (forthcoming) consider a general dynamic agency setup in which investment is history-dependent through the continuation utility, a feature that is also present in my simple analysis.

\section{Model}

\subsection{Technology and preferences}

A country represented by its government $(G)$ possesses an immovable investment opportunity (such as a gold mine), but lacks expertise to run the project in an efficient way relative to a multinational firm $(F){ }^{8}$ Project output at time $t$ is solely a function of the capital stock at time $t$, i.e., $Y_{t}=Y_{i}\left(K_{t}\right)$. The project can either be run using the efficient firm production technology $Y_{F}(K)$ or the second-best government technology $Y_{G}(K)$. Both production functions are assumed to satisfy Inada conditions. Current period

\footnotetext{
(footnote continued)

and they only focus on the equilibrium contract which gives the entire surplus to the firm.

${ }^{7}$ She develops a model of debt contracts with short-term commitment, in which she finds that social welfare is non-monotonic in the borrower's outside option. This non-monotonicity results from the participation constraints of the lender and the borrower, respectively.

${ }^{8}$ The productivity gap could also result from the lack of managerial incentives under public ownership (as in Biais and Perotti, 2002). Whether the firm is actually from another country does not matter in terms of the model. This interpretation should be viewed as a motivation for the most relevant empirical implications.
} 


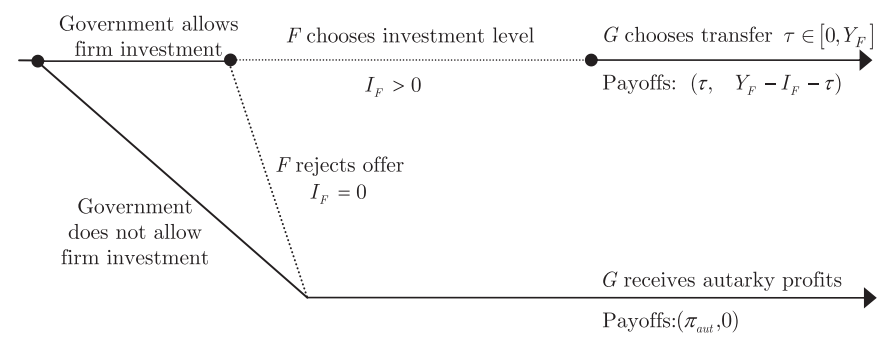

Fig. 1. The graph plots the timeline of the stage game. Each period the government decides whether to allow firm investment or not. If it allows firm investment, the firm can either reject the offer or invest some amount $I_{F}>0$. If the firm chooses $I_{F}>0$, it generates output $Y_{F}\left(I_{F}\right)>0$. In this case, the firm pays taxes $\tau$, so that its net cash flow is $Y_{F}-I_{F}-\tau$. The government can always confiscate output, i.e., effectively choose any total transfer $\tau \leq Y_{F}$. If the firm does not invest, the government uses its autarky production technology and generates cash flows of $\pi_{\text {aut }}$. Firm cash flows are zero.

investment $I_{t}$ is assumed to add to the current period capital stock $K_{t}$ :

$K_{t}=I_{t}+K_{t-1}(1-\delta)$.

All figures in this paper are based on the functional form: $Y_{F}(K)=K^{\alpha}$ where $0<\alpha<1$ and $Y_{G}(\rho, K)=\rho^{1-\alpha} K^{\alpha}$ where $\rho<1$. The productivity gap between the firm and the government governed by the parameter $\rho$ can be interpreted as the difference between local expertise and international best practice. ${ }^{9}$

Both the government and the firm are risk neutral and maximize the net present value of cash flows $C_{t}^{(i)}$ over an infinite horizon with respective discount factors $\beta_{F}$ and $\beta_{G}$. Government cash flows are given by taxes $\tau_{t}$, whereas firm cash flows are given by profits: $\pi_{t}=Y_{t}-I_{t}-\tau_{t}$ :

$V^{(i)}=\sum_{t=0}^{\infty} \beta_{i}^{-t} C_{t}^{(i)}$.

\section{Assumption 1. $\beta_{G}<\beta_{F} \leq 1$.}

The firm's discount factor $\beta_{F}$ is exogenously determined by the capital market. Relative impatience of the government can be viewed as a reduced-form implication of two distinct mechanisms. First, political economy considerations suggest that the chance of government turnover effectively increases the discount rate of the government in place (see Aguiar, Amador, and Gopinath, 2009). Secondly, as in Hart and Moore (1994), higher effective discounting can be caused by a combination of financial constraints and profitable reinvestment opportunities. Section 3.8 discusses the implications of alternative assumptions about the relative discount factors.

\subsection{Dynamic hold-up}

I consider a dynamic game with perfect public information between the firm and the government. History at time $t$ is defined by the sequence of investments and transfers,

$h^{t} \equiv\left\{\left(\tau_{s}, I_{S}\right)\right\}_{S=1}^{t}$,

\footnotetext{
${ }^{9}$ For simplicity, I assume that the firm has already made the decision about the optimal production technology. It is beyond the scope of this paper to analyze the choice of production technology, which creates endogenous comparative advantage.
}

with $h^{0}$ representing the empty history. The formal notion of credibility refers to the equilibrium concept of subgame perfection. The terms sustainable, self-enforcing, or subgame perfect will be used interchangeably throughout the paper. There is two-sided lack of commitment: The government can confiscate the output from the project $Y$ and the depreciated capital stock at the end of each period. The firm can leave the country. The commitment problem of the government could be eliminated if it were able to pledge sufficient outside collateral. ${ }^{10}$ Consistent with the assumption of relative impatience, the government is liquidity constrained and thus cannot pledge sufficient collateral. The timeline for the special case of full depreciation $(\delta=1)$ reveals the sequence of actions in each period (see Fig. 1).

\section{Basic analysis}

\subsection{Repeated game setup}

If $\delta=1$, the dynamic game formally collapses to a standard infinite repeated game. While this assumption does not capture the (quantitatively) important characteristics of most investments, it greatly simplifies the exposition of the relevant model mechanics. The case $\delta<1$ is discussed in Section 3.7.

It is useful to define the static optimum investment level $\hat{I}$, output $\hat{Y}$, and associated per-period profits $\hat{\pi}$ as

$\hat{I} \equiv \arg \max \left(Y_{F}(I)-I\right)$,

$\hat{Y} \equiv Y_{F}(\hat{I})$

$\hat{\pi} \equiv \hat{Y}-\hat{I}$.

The fraction of autarky profits to the efficient profits, $\rho=\pi_{\text {aut }} / \hat{\pi}$ (where $0<\rho<1$ ), is a sufficient statistic for the government's inferior production technology. In the isolated analysis of the stage game, the government is the last mover. It would always choose to collect the entire firm cash flows $\tau=Y$, inducing the firm to lose the upfront investment $I$. Since the firm can get at least a payoff of zero by refusing to invest in the project, a Nash equilibrium of the stage game features no firm

\footnotetext{
${ }^{10}$ An example is money in a Swiss bank account, which is transferred to the firm in case of a violation of its property rights.
} 
investment. The associated autarky per-period cash flows are $\pi_{a u t}$ for the government and zero for the firm. By unraveling, a finite repetition of the stage game $\Gamma^{n}$ does not make firm investment sustainable. However, in the infinite-horizon setup, more efficient outcomes may be feasible.

\subsection{Firm investment}

Private firm investment is feasible if the firm's threat of leaving the country hurts the government just enough that it refrains from expropriating firm assets. Following the idea of Abreu (1988), the whole set of subgame perfect equilibria can be enforced with the threat of the worst possible subgame perfect equilibrium (autarky). ${ }^{11}$

The best possible one-period deviation of the government is to confiscate the entire output $Y$. After firm investment $I$ is sunk, the outside option of the government is given by: $Y+\beta_{G} v_{\text {aut }}$. I define $v_{\text {aut }}$ as the present value of autarky profits:

$v_{\text {aut }} \equiv \frac{\pi_{a u t}}{1-\beta_{G}}$.

Formally, the following incentive constraint of the government has to be satisfied for some investment level $I$ :

$\frac{Y-I}{1-\beta_{G}} \geq Y+\beta_{G} v_{\text {aut }}$.

Proposition 1. If the relative productivity of the government exceeds the threshold level $\tilde{\rho}=\max _{I}\left(Y_{F}(I)-\beta_{G}^{-1} I\right) / \hat{\pi}<1$, autarky is the only subgame perfect equilibrium.

Proof. See Appendix B.1.

Using the production function $Y_{F}(I)=I^{\alpha}$ yields a threshold level of $\beta_{G}^{\alpha /(1-\alpha)}$. This proposition has two interpretations. First, for any given discount factor $\beta_{G}$, sufficiently low relative ability $\rho$ makes firm investment sustainable. Intuitively, the threat of autarky is more effective if the government is unable to produce on its own. Secondly, for any given level of $\rho$, there exists a patience level $\beta_{G}$ which enables firm investment. Sustainability of firm investment does not depend on the firm's discount rate because the firm makes zero (economic) profits each period in the relevant stationary allocation.

\subsection{Recursive formulation}

We now focus on the case in which firm investment is feasible, i.e., $\rho \leq \tilde{\rho}$, to describe the (non-trivial) Pareto set of non-autarky equilibria. The optimal sequence of investment and transfers $\left\{\left(\tau_{s}, I_{s}\right)\right\}_{s=0}^{\infty}$ can be solved for via recursive formulation using standard dynamic programming techniques. The state variable, $v$, is given by the net

\footnotetext{
${ }^{11}$ It is standard in the literature to use the worst subgame perfect equilibrium or autarky as the punishment equilibrium. The main results of my paper do not hinge on this assumption. As shown in the Online Appendix, all subgame perfect equilibria described in the text are also renegotiation-proof provided that the government is sufficiently productive.
}

present value (NPV) of transfers to the government at the beginning of period $t .^{12}$ This promised value is a sufficient statistic for the entire history $h^{t-1}$.

Let $V_{F}(v)$ denote the net present value of the firm given the promised value $v$. The current period value to the government can be expressed as the sum of current period transfers $\tau$ and the discounted continuation value $w$. If the firm does not pay any taxes today $(\tau=0)$, it needs to pay higher taxes in the future $(w>v)$. The firm value $V_{F}(v)$ can be expressed as the sum of current period net profits $Y-I-\tau$ and the discounted firm value given next period's promised value $w$ :

$v=\tau+\beta_{G} w$

$V_{F}(v)=Y-I-\tau+\beta_{F} V_{F}(w)$.

Definition 1. The Pareto region of $v$ is defined as the compact domain $\left[v_{\min }, v_{\max }\right]$ in which $V_{F}(v)$ is downward sloping.

Definition 2. The Pareto frontier is given by: $\left\{\left(v, V_{F}(v)\right)\right.$ s.t. $\left.v \in\left[v_{\min }, v_{\max }\right]\right\}$.

By the definition of Pareto optimality, the value to the firm $V_{F}$ must be strictly decreasing in the promised value to the government. An efficient allocation is therefore uniquely determined by the promised value $v$. The goal of the recursive formulation is to trace out the entire set of the Pareto frontier $V_{F}(v)$ (see preview of solution in Fig. 2) and determine the optimal current period actions $I(v), \tau(v)$ as well as the promised value for next period $w(v)$. Thus, while the frontier $V_{F}(v)$ in itself is time-invariant, investment decisions and taxes are history-dependent and change over time in response to the optimal dynamic evolution of $v$. The mathematical problem can be stated as follows:

$V_{F}(v)=\max _{I, \tau, w} Y-I-\tau+\beta_{F} V_{F}(w)$ s.t.

\begin{tabular}{lll}
$\#$ & Constraint & Lagrange multiplier \\
\hline$(1)$ & $\tau+\beta_{G} w \geq v$ & $\lambda_{P K}$ \\
$(2)$ & $\tau+\beta_{G} w \geq Y_{F}(I)+\beta_{G} v_{\text {aut }}$ & $\lambda_{I C}$ \\
$(3)$ & $V_{F}(w) \geq 0$ & $\beta_{F} \lambda_{P C}$ \\
$(4)$ & $\beta_{G} \lambda_{I R}$ \\
$(5)$ & $\lambda_{\tau}$ \\
Initial conditions & \\
$V_{F}\left(v_{0}=Y-I-\tau+\beta_{F} V_{F}(w) \geq 0\right.$ & \\
$v_{0} \geq v_{\text {aut }}$ &
\end{tabular}

Without loss of generality, the problem is stated from the perspective of the firm. The entire set of efficient contracts can be traced out by varying $v$. The naming of the Lagrange multipliers follows the convention of Ljungqvist and Sargent (2004). The first constraint is the promise-keeping constraint $(P K)$. It ensures that the current period transfer $\tau$ and the promised continuation value $w$ yield at least the promised value of $v$ to the government. ${ }^{13}$ The second constraint (IC) ensures that the

\footnotetext{
12 If $\delta<1$ (see Section 3.7), the initial capital stock becomes an additional state variable.

13 This constraint must always bind in the Pareto region.
} 


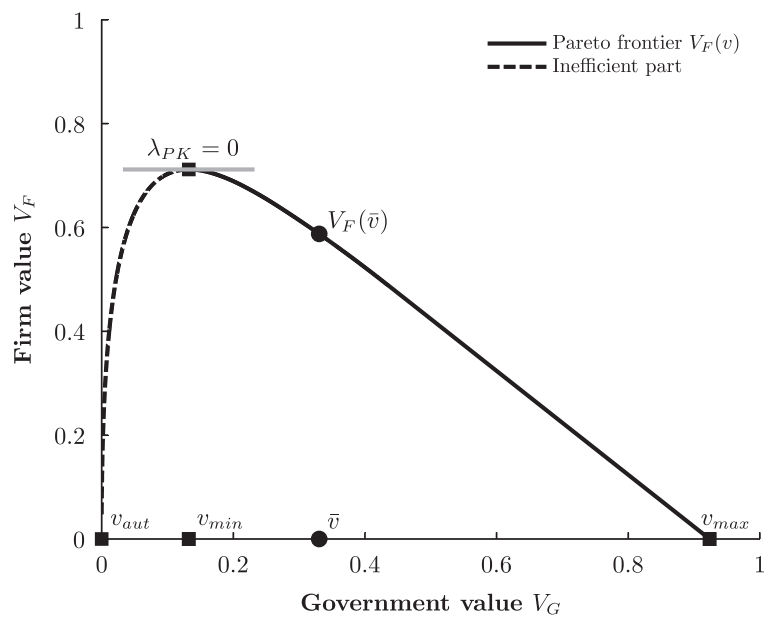

Fig. 2. This graph plots the maximized firm value $V_{F}$ as a function of the government value $V_{G}$. The inefficient part of the frontier refers to the region where an increase in $V_{G}$ is associated with an increase in $V_{F}$. The minimum value to the government on the Pareto frontier, i.e., $v_{\min }$, is characterized by the point where the slope $\lambda_{P K}$ is equal to zero. The firm value in the steady state is given by $V_{F}(\bar{v})$. At $v_{\max }$, the firm value is equal to zero. In this example, the government is assumed to be unable to operate the project, i.e., $\rho=0$, such that $v_{\text {aut }}=0$. The other parameters satisfy $\beta_{G}=0.8, \beta_{F}=0.9$, and $\alpha=0.7$ using the production function $Y_{F}(I)=I^{\alpha}$.

government finds it incentive compatible to honor the terms of the contract. The present value of taxes $\tau+\beta_{G} w$ must be higher than the value implied by the optimal deviation $Y_{F}(I)+\beta_{G} v_{a u t}$. The third constraint $(P C)$ ensures firm participation in every period. The firm cannot commit to stay in the country if the net present value becomes negative. The fourth constraint (IR) represents the individual rationality constraint of the government. Next period's promised value must yield a higher value than autarky. The last constraint implies that the government is liquidity constrained and cannot provide subsidies. ${ }^{14}$ In contrast, the firm is assumed to be financially unconstrained and does not face any liquidity constraints. The initial conditions simply ensure that both parties are better off than in autarky. It will become clear later that this restriction on $v_{0}$ causes the $I R$ constraint of the government to be slack at any future point in time $\left(\lambda_{I R}=0\right){ }^{15}$ Using these simplifications $\left(\lambda_{I R}=0\right)$, the Lagrangian can be stated as follows:

$$
\begin{aligned}
L= & Y_{F}(I)-I-\tau+\beta_{F} V_{F}(w) \\
& +\lambda_{P K}\left[\tau+\beta_{G} w-v\right]+\lambda_{I C}\left[\tau+\beta_{G} w-Y_{F}(I)-\beta_{G} v_{a u t}\right] \\
& +\beta_{F} \lambda_{P C} V_{F}(w)+\beta_{G} \lambda_{I R}\left[w-v_{a u t}\right]+\lambda_{\tau} \tau .
\end{aligned}
$$

The non-negative Lagrange multipliers are functions of the promised value $v$. The first-order conditions with

\footnotetext{
14 The mechanics of the contract are essentially unaffected if one allows for the payment of ex post subsidies. It will become clear later that subsidies only impact the speed of adjustment to the stationary allocation. Liquidity constraints of the firm would also just affect the transition dynamics.

${ }^{15}$ The reasoning is as follows. If the current period promised value $v$ is small (close to $v_{\text {aut }}$ ), the optimal dynamics imply backloading of transfers to the government $(w>v)$. Therefore, if $v>v_{a u t}$ is satisfied, then $w>v_{\text {aut }}$ is also satisfied.
}

respect to $I, \tau$, and $w$ imply

$$
\begin{aligned}
& I: Y_{F}^{\prime}(I)\left(1-\lambda_{I C}\right)-1=0, \\
& \tau: \lambda_{P K}+\lambda_{I C}+\lambda_{\tau}-1=0, \\
& w: \beta_{F}\left[V_{F}^{\prime}(w)\left(1+\lambda_{P C}\right)+\frac{\beta_{G}}{\beta_{F}}\left(\lambda_{P K}+\lambda_{I C}\right)\right]=0 .
\end{aligned}
$$

In addition, the complementary slackness conditions have to hold. By the envelope condition, the Lagrange multiplier on the $P K$ constraint $\lambda_{P K}$ represents the shadow price of promising an additional unit of value to the government (in firm value units):

$-V_{F}^{\prime}(v)=\lambda_{P K}$.

Graphically, the Lagrange multiplier $\lambda_{P K}$ represents the slope of the value function evaluated at the current period promised value $v$ (see Fig. 2).

Lemma 1. The value function $V_{F}(v)$ is concave.

Proof. The concavity of the value function follows directly from the strict concavity of the production function.

Due to concavity of the objective function, the transition law for the promised value $w(v)$ is implicitly determined through the first-order Markov process of the slope $\lambda_{P K}$ :

$\lambda_{P K}^{*}=\frac{\beta_{G}}{\beta_{F}} \frac{\lambda_{P K}+\lambda_{I C}}{1+\lambda_{P C}}$.

\subsection{Steady state}

In this section, I characterize the steady state of all efficient contracts, the unique stationary contract on the Pareto frontier $(w(\bar{v})=\bar{v}) .{ }^{16}$

Proposition 2. There exists a unique stationary contract on the Pareto frontier which yields the government a value of $\bar{v}$ such that

$Y_{F}^{\prime}(\bar{I})=\left(1+\bar{\lambda}_{P C}\right) \frac{\beta_{F}}{\beta_{G}}=\frac{1}{\bar{\lambda}_{P K}}$,

$\bar{\tau}=\left(1-\beta_{G}\right) Y_{F}(\bar{I})+\beta_{G} \pi_{\text {aut }}$.

The contract is interior $\left(\bar{\lambda}_{P C}=0\right)$ if $\rho<\bar{\rho}$ or a corner contract $\left(\bar{\lambda}_{P C}>0\right)$ if $\bar{\rho}<\rho<\tilde{\rho}$ where $\bar{\rho}$ satisfies $\left(\bar{Y}-\beta_{G}^{-1} \bar{I}\right) / \hat{\pi}$ such that $Y_{F}^{\prime}(\bar{I})=\beta_{F} / \beta_{G}$.

Proof. See Appendix B.2.

Thus, at the steady state, the marginal product of investment satisfies $Y_{F}^{\prime}(\bar{I}) \geq \beta_{F} / \beta_{G}>1$ and corresponds to the inverse of the slope of the value function. Investment is always below the static optimum, satisfying $Y_{F}^{\prime}(\hat{I})=1$, due to relative impatience of the government and the non-negativity of the Lagrange multiplier $\bar{\lambda}_{P C}$. Taxes in the steady state $\bar{\tau}$ are a weighted average of output, the deviation payoff, and autarky profits. The weight on output, $\left(1-\beta_{G}\right)$, is just high enough to incentivize the government not to expropriate. I distinguish between two types of stationary contracts: An

\footnotetext{
${ }^{16}$ Without liquidity constraints of the government, the steady state would be reached in the second period. This is related to Levin (2003).
} 
interior stationary contract is defined as a stationary contract with strictly positive firm profits $\left(\bar{\lambda}_{P C}=0\right)$. A corner stationary contract is referred to as a contract where the firm just breaks even in the steady state $\left(\bar{\lambda}_{P C}>0\right)$. Intuitively, the interior stationary contract obtains if the incentive problem of the government is not "severe," as determined by the relative productivity of the government.

The impatience channel causes "efficient" investment distortions. Intuitively, impatience gives rise to a second source of surplus from the relationship apart from the technology advantage of the firm. In the interior steady state, the gains from trading across time, driven by the degree of relative impatience, are equal to the marginal product of investment, i.e., $Y_{F}^{\prime}(\bar{I})=\beta_{F} / \beta_{G}$. Thus, while investment at the static optimum, $\hat{I}$, may be sustainable, both parties can be made better off if the government receives such a large upfront payment today that the incentive constraint binds in the future. The marginal benefit of providing an immediate loan to the government of $\$ 1$ equals the marginal productivity of investing this dollar in the production technology.

In the corner steady state, additional "inefficient" investment distortions are caused by the firm participation constraint. Only in this case, lack of commitment on the side of the firm matters for the equilibrium allocation. If the firm could commit to stay in the country and continue operating once the NPV of the project has become negative, these investment distortions would not arise.

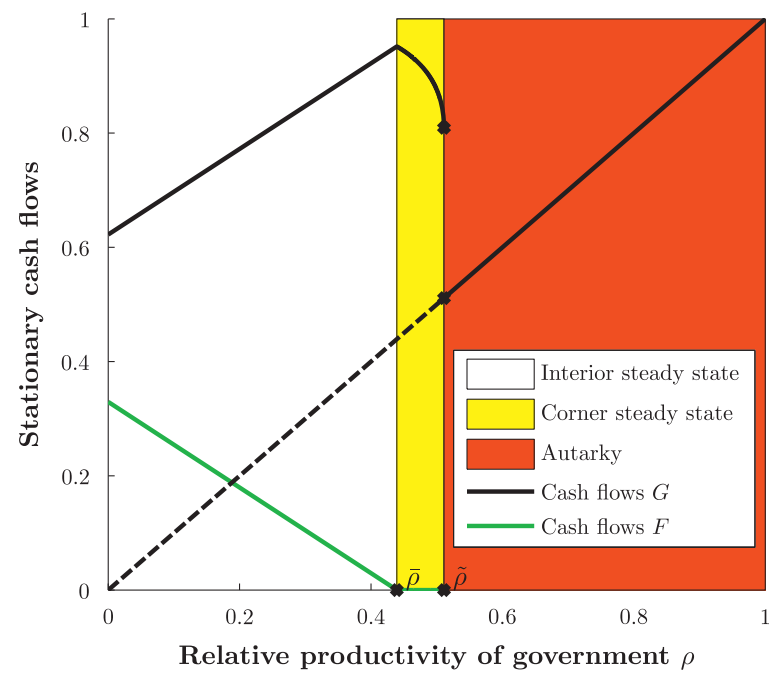

Fig. 3. This graph plots the stationary cash flows to the government and the firm. The production function is normalized by a constant $A$ such that the firm could produce stationary profits of one, i.e., $\max _{I} A I^{\alpha}-I=1$. If the government's technology is sufficiently inferior, i.e., $\rho \leq \bar{\rho}$, the steady state is interior and output satisfies $Y_{F}^{\prime}(I)=\beta_{F} / \beta_{G}$. In this region, an increase in government efficiency increases stationary taxes and reduces firm profits accordingly. Once firm profits are zero, i.e., for $\rho=\bar{\rho}$, the government's incentive to expropriate cash flows can only be tamed by reducing investment (corner steady state). This causes investment distortions and reduces surplus. At $\rho=\tilde{\rho}$, the government's technology is so advanced such that an arbitrarily small increase in its ability will make firm investment unsustainable and the government needs to operate the project with its autarky production technology. This switch to the inefficient production technology generates a discontinuity in government cash flows. Once the government produces in autarky, an increase in $\rho$ increases cash-flows to the government unambiguously. The parameters satisfy $\beta_{G}=0.75, \beta_{F}=0.85$, and $\alpha=0.7$.
The sign of the comparative statics of long-run government welfare, $\bar{v}=\bar{\tau} /\left(1-\beta_{G}\right)$, with regards to its relative production efficiency $\rho$ depend on whether the corner steady state or the interior steady state obtains.

Proposition 3. Comparative statics of technology $\rho$ : Stationary transfers to the government, $\bar{\tau}$, are

(a) increasing in $\rho$ if the interior steady state obtains $(\rho<\bar{\rho})$

(b) decreasing in $\rho$ if the corner steady state obtains $(\bar{\rho}<\rho<\tilde{\rho})$.

\section{Proof. See main text.}

Fig. 3 illustrates the steady state welfare comparative statics of relative productivity. The parameter region of $\rho$ is divided into three intervals corresponding to the interior steady state $(0 \leq \rho<\bar{\rho})$, the corner state steady state $(\bar{\rho} \leq \rho \leq \tilde{\rho})$, and autarky $(\tilde{\rho}<\rho \leq 1)$. Stationary firm profits are linearly decreasing with slope $\beta_{G}$ until the participation constraint becomes binding at $\bar{\rho}$. Stationary profits remain flat at zero even though the firm is still producing in the region between $\bar{\rho}$ and $\tilde{\rho}$.

Government cash flows increase linearly in relative productivity with slope $\beta_{G}$ as long as the firm participation constraint does not bind $(\rho<\bar{\rho})$. In this case, investment, and hence total surplus, are unaffected by relative productivity. However, the better outside option allows the government to extract a greater fraction of the total surplus. Once it extracts all the surplus $(\rho \geq \bar{\rho})$, cash flows decrease continuously with slope $\left(Y_{F}^{\prime}(I)-1\right) /\left(\beta_{G}^{-1}-Y_{F}^{\prime}(I)\right)$ as the participation constraint of the firm leads to additional investment distortions. ${ }^{17}$ This non-monotonicity would not occur in models with a committed firm (principal), such as in DeMarzo and Fishman (2007). At $\tilde{\rho}$ a discrete jump occurs because the efficient production technology of the firm is no longer available and the project is operated with the second-best autarky technology. Once autarky is the only feasible option, cash flows increase one-to-one with relative productivity.

These comparative statics reveal that an increase in relative productivity can have different welfare implications, depending on the current level of technology. Even though technology acquisition is formally not part of the model, one can use these implications to shed light on the incentives to invest in research and development (R\&D), or more generally, in education. Close to the threshold level $\bar{\rho}$, the government has very little incentive to deploy costly resources to R\&D. A marginal increase in its technology level makes the incentive problem so severe that the firm has to reduce investment. On the other hand, the firm always benefits from a successful upgrade of its relative technology level (lower $\rho$ ).

\subsection{Transition dynamics}

Despite the stationary physical environment, the optimal self-enforcing contract has non-trivial dynamic features.

${ }^{17}$ The slope can be determined using the implicit function theorem. As $\rho$ approaches $\tilde{\rho}$, the slope approaches $-\infty$ as $Y_{F}^{\prime}(\tilde{I})=\beta_{G}^{-1}$. 
Lemma 2. The stationary contract is globally stable.

Proof. See Appendix B.3.

Lemma 2 implies that promised values rise over time $(v<w)$ if the contract is initialized below the steady state value $(v<\bar{v})$, and decrease over time if the initial value is above the steady state $(v>\bar{v})$. The latter case is only possible if the stationary contract is interior.

These distinct dynamics are driven by two competing forces. The efficient provision of intertemporal incentives requires the government to obtain backloaded transfers. The intuition goes back to Becker and Stigler (1974) as well as Harris and Holmstrom (1982). Backloading works, because deferred rewards provide incentives for current and future periods. Implicitly, the firm acts as a savings bank for the government, where the deposit is used as collateral, a discipline device to induce cooperation. The competing force to the incentive problem is given by relative impatience of the government (efficiency). The ratio $\beta_{G} / \beta_{F}$ can be arbitrarily close to one. Relative impatience suggests that the government should obtain frontloaded payoffs, such that the firm acts as a quasilender to the government.

The resulting contract dynamics depend on whether the incentive problem or impatience (efficiency) dominates. At the stationary contract, the effects of incentives and efficiency are offset. To the left of the steady state, the government obtains relatively small current promises $v$, which implies that the incentive problem dominates. This results in backloaded transfers. To the right of the steady state, the incentive problem is second-order, such that relative impatience dominates and the firm acts as a sovereign debt lender. ${ }^{18}$

Proposition 4 (Optimal continuation values).

(a) For $v<\beta_{G} \bar{v}$, promised values are raised each period at the gross interest rate $\beta_{G}^{-1}$ until the steady state is reached.

(b) Otherwise, the steady state is reached in the next period. $w(v)= \begin{cases}\beta_{G}^{-1} v & \text { for } v<\beta_{G} \bar{v}, \\ \bar{v} & \text { for } v \geq \beta_{G} \bar{v} .\end{cases}$

Proof. See Appendix B.4.

Given the function $w(v)$, the optimal transfer and investment schedule $I(v)$ satisfy:

Proposition 5. Optimal investment and transfer policy:

$\tau(v)= \begin{cases}\tau_{\min }=0 & \text { for } v<\beta_{G} \bar{v}, \\ v-\beta_{G} \bar{v} & \text { for } v \geq \beta_{G} \bar{v},\end{cases}$

$I(v)= \begin{cases}Y_{F}^{-1}\left(v-\beta_{G} v_{a u t}\right) & \text { for } v<\hat{v}, \\ \hat{I} & \text { for } v \geq \hat{v} .\end{cases}$

\footnotetext{
${ }^{18}$ In contrast to the setup of Bulow and Rogoff (1989b), the firm can expect to receive a payback on the loan due to its technology advantage on the production side.
}

Proof. See Appendix B.4.

The optimal continuation values (Proposition 4) and the policy functions (Proposition 5) generate the dynamics of observable variables:

Corollary 1 (Joint dynamics of investment and transfers). Backloading: For promised values lower than the stationary level $(v<\bar{v})$, investment is strictly increasing over time. Transfers are zero unless the stationary contract is reached in the next period.

Frontloading: For promised values greater than the stationary level $(v>\bar{v})$, investment and transfers are above the steady state level only in the first period.

It is instructive to first explore the case when the constraints on the transfer policy $\left(\tau_{\min } \leq \tau\right)$ are lifted or do not bind $\left(\lambda_{\tau}=0\right)$. Since there are no adjustment costs, it is efficient to directly "jump" to the steady state. This is similar to the stationarity result of Levin (2003). The optimal transfer $\tau$ has to ensure that the promised value $v=\tau+\beta_{G} \bar{v}$ is delivered. Taking the liquidity constraints into account, transfers are chosen such that the contract takes the largest step towards the steady state contract. The optimal policies are plotted in Fig. 4. Due to the asymmetry in liquidity constraints, the (speed of the) transition dynamics depend on the initial promised value. If the government receives more than in the steady state $v>\bar{v}$, the firm will make an immediate one-time payment to the government that ensures that the stationary allocation is reached in the next period. This one-time payment can also be interpreted as the initial sales price of the project. In contrast, if the initial value of the project to the government is sufficiently low $\left(v<\beta_{G} \bar{v}\right)$, the constraint on the minimum transfer binds, i.e., $\tau=\tau_{\min }=0$. An (efficient) subsidy is precluded by the government's liquidity constraint. In this region the firm keeps its

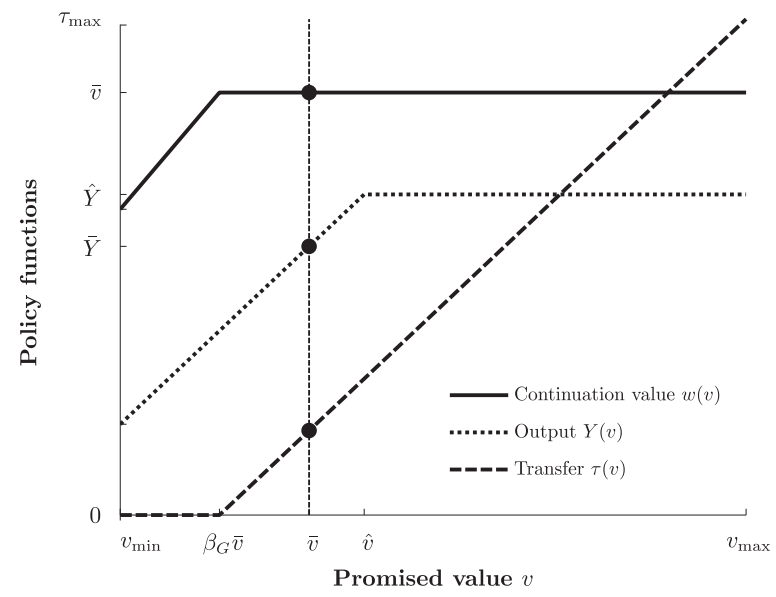

Fig. 4. This graph plots policy functions for continuation values, output, and transfers. Initially, the continuation value $w(v)$ is an increasing function of the promised value until the stationary value $\bar{v}$ is reached in the consecutive period, i.e., whenever $v>\beta_{G} \bar{v}$. This is also the threshold at which the firm starts paying taxes. From then on, an increase in $v$ increases current-period transfers $\tau$ one-to-one. Output also increases one-to-one with the promised value until the static optimum output level $\hat{Y}$ is reached, i.e., at $\hat{v}$. The parameters satisfy $\beta_{G}=0.8, \beta_{F}=0.9$ $\alpha=0.6$, and $\rho=0.3$. 


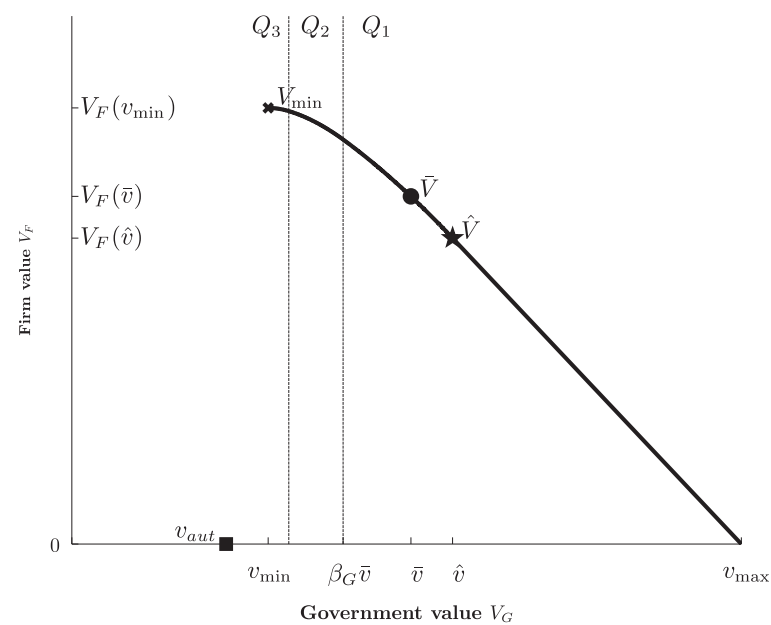

Fig. 5. This graph plots the Pareto frontier implied by the policy functions illustrated in Fig. 4, i.e., the parameters satisfy $\beta_{G}=0.8$, $\beta_{F}=0.9, \alpha=0.6$, and $\rho=0.3$. The frontier is strictly concave for $v<\hat{v}$ and linear for $v \geq \hat{v}$. For each $v \in Q_{i}$, it takes $i$ periods until the stationary allocation $\bar{V}$ is reached.

promise solely by raising the continuation value to $w=\beta_{G}^{-1} v$, which is the current value $v$ plus the required interest. It is possible to define intervals $Q_{i}$ (see Fig. 5) such that for each $v \in Q_{i}$ it takes exactly $i$ periods to reach the steady state:

$Q_{i} \equiv \begin{cases}{\left[\beta_{G} \bar{v}, v_{\max }\right]} & \text { for } i=1, \\ {\left[\beta_{G}^{i} \bar{v}, \beta_{G}^{i-1} \bar{v}\right)} & \text { for } i \geq 2 .\end{cases}$

For promised values larger than $\beta_{G} \bar{v}$, the continuation value is given by the steady state value, such that transfers $\tau$ have to increase one-to-one with $v$. This ensures that the firm promise to the government $\left(\tau+\beta_{G} \bar{v}=v\right)$ is kept. As long as the incentive constraint of the government binds, output also increases one-to-one with $v$. This follows from the $P K$ constraint and the IC constraint $\left(Y+\beta_{G} v_{a u t}=v\right)$. Investment is simply given by $Y_{F}^{-1}\left(v-\beta_{G} v_{\text {aut }}\right)$. If the promise is above $\hat{v}=\hat{Y}+\beta_{G} v_{\text {aut }}$, efficient investment and efficient output is feasible. In this region $(v>\bar{v})$, the frontier is linear with slope -1 . Given the optimal policy functions, it is now possible to determine a closed-form solution for the Pareto frontier (see Fig. 5). ${ }^{19}$

The dynamics on the frontier over time are uniquely determined by the transition law for the promised value. The relation between $v_{0}$ and the steady state value $\bar{v}$ determines the observable dynamics. The model itself does not predict a particular contract starting point $v_{0}$ within the Pareto region $\left[v_{\min }, v_{\max }\right]$. The initial surplus division can be interpreted as the outcome of a simple bargaining game such as in Hart and Moore (1998). Thus, high firm bargaining power translates into lower initial promised values to the government, $v_{0}<\bar{v}$ (backloading). Low firm bargaining power results in high initial values to the government. In this case, frontloading occurs if the stationary contract is interior.

${ }^{19}$ The derivation and functional form do not provide any additional insight.
An alternative mechanism to generate a starting point on the Pareto frontier is given by an auction process. Suppose there are multiple firms with different technological capabilities which put in bids to the government $v_{0}$ for the exclusive right to operate the project. The technology leader wins the auction. The initial promised value to the government is determined by the break-even condition of the second-best producer. With this type of Bertrand competition among producers, a closer gap between the two leading producers results in higher values to the government (frontloading). In contrast, if the productivity gap between the first- and second-best producers is high, the initial promised value to the government is low (backloading). ${ }^{20}$ These ideas can also be framed in terms of uniqueness. If the firm is the essential ingredient providing the government with a unique investment opportunity, it is more likely that the initialization is favorable for the firm. In this case, the firm can exploit competition among countries to extract higher cash flows (backloading). If the investment opportunity is unique to the country, such as through the existence of natural resources or in terms of market access, the government can exploit competition among firms.

\subsection{Comparative statics}

Fig. 6 illustrates the comparative statics of technology in two ways. The left panel plots the entire frontier for various levels of relative productivity. The right panel plots focal points of the frontier as a function of relative productivity. The contract $V_{\min }\left(V_{\max }\right)$ represents the least (most) favorable contract for the government. The concavity parameter and discount factors are identical in both panels, so that the value of $v_{\text {min }}$ for some level of $\rho=\breve{\rho}$ in the left panel coincides with the value of $v_{\min }$, in the right panel when $\rho=\breve{\rho}$.

The left panel reveals that lower relative productivity causes the Pareto frontier to move outward. Both parties can be made better off at the initialization of the contract. The right panel plots the endogenous (incentive compatible) level of surplus, measured by $v_{\max }$, as well as the minimum value that the government can extract, as measured by $v_{\min }$. Total surplus is highest for $\rho=0$ and decreasing in $\rho$, whereas the higher threat point associated with higher productivity implies the opposite relationship for $v_{\min }$. Hence, depending on its bargaining power, the government prefers to be technologically strong or weak. For low bargaining power, the threat point motive dominates and the government is better off with higher ability. For high bargaining power, total surplus considerations dominate and the government prefers to be of low ability. While this reduces stationary payments, $\bar{\tau}$, (see dashed purple line and also Fig. 3) it allows for the efficient upfront transfer of funds to the impatient government.

\footnotetext{
${ }^{20}$ An interesting question in the multiple firm setup is whether the government can use the second-best firm technology instead of its autarky technology as a threat point. This can be ruled out if there exists a continuum of firms with the second-best technology. In this case, the second-best producer can always be replaced by a company with the same technology and will never invest.
} 

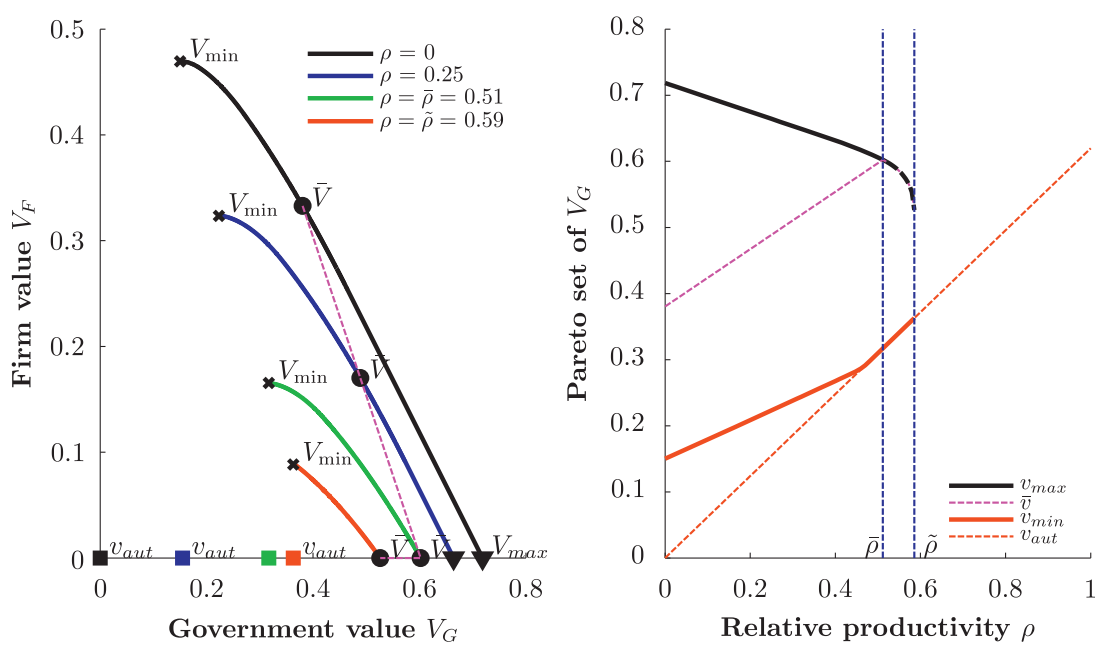

Fig. 6. The left panel of the graph plots the entire Pareto frontier for various levels of $\rho$. The higher $\rho$, the smaller the set of sustainable values. For $\rho \leq \bar{\rho}$, the interior steady state is reached. The case $\rho=\tilde{\rho}$ plots the Pareto frontier for the largest possible level of relative productivity that allows for firm investment. The right panel plots the sustainable range of values for the government, i.e., $v_{\min }$ and $v_{\max }$. An increase in relative productivity increases $v_{\min }$, but reduces $v_{\max }$ (as long as firm investment is ensured). For $\rho$ sufficiently large, $v_{\text {min }}$ coincides with the autarky value $v_{\text {aut }}$. This implies $\lambda_{P K}\left(v_{\min }\right)>0$. For both panels the parameters are $\beta_{G}=0.7, \beta_{F}=0.8$, and $\alpha=0.6$.

\subsection{Capital stock and depreciation}

The previous analysis assumed that the capital stock depreciates fully in each period. Now consider an arbitrary depreciation rate $\delta$ (see Eq. (1)). As formally shown in the Online Appendix, all previous results are still valid for $\delta<1$. This extension provides two additional insights. First, it predicts that a high (low) initial capital stock of the project is associated with frontloading (backloading). Secondly, a higher depreciation rate of capital makes firm investment less likely to be sustainable.

Intuitively, a lower initial capital stock shifts the Pareto frontier, which is now also a function of the capital stock, downwards. Fig. 7 plots the Pareto frontier $V_{F}(v, K)$ for two different levels of the capital stock. The upper graph refers to the frontier with (beginning-of-period) capital at the steady state level, i.e., $V_{F}(v,(1-\delta) \bar{K})$. The lower graph plots the capital stock with no initial capital stock $V_{F}(v, 0)$, which is simply a downward shift by $(1-\delta) \bar{K}$. The law of motion of the capital stock is driven by the promised value. Thus, rather than moving on the same frontier (as in the repeated game setup), the evolution of the promised value implies moving across frontiers.

A lower initial capital stock decreases the NPV of the project of the firm for any given promised value to the government. The initial break-even constraint of the firm implies that the feasibility of up-front payments to the government is restricted. In the above example with no starting capital, the project can only be started if the initial promised value is below the steady state value $\bar{v}$, i.e., in the backloading region. Thus, the lower the initial capital stock, the more likely the ex ante participation constraint of the firms is violated for a given promised value. Empirically, this predicts a positive (partial) correlation between backloading and the initial level of the capital stock.

At a first glance, one would suggest that a fast depreciating capital stock decreases the incentive to

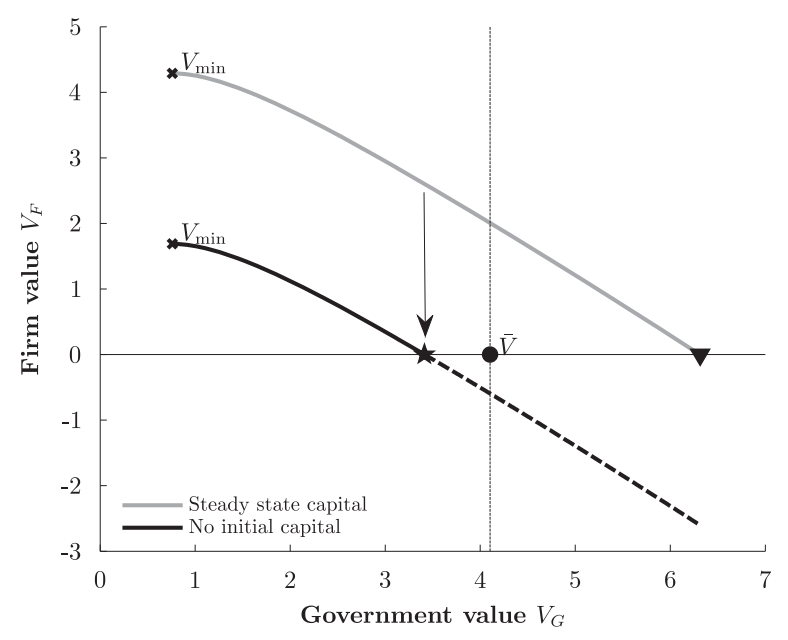

Fig. 7. This graph plots the Pareto frontier for two levels of the initial capital stock (no initial capital and the steady state level). A lower capital stock shifts the frontier downwards in a parallel fashion. The parameters are $\beta_{G}=0.7, \beta_{F}=0.8, \alpha=0.7, \rho=0$, and $\delta=0.2$.

expropriate (because a smaller fraction of the capital stock can be stolen). However, the model predicts that controlling for the relative level of productivity, faster depreciation increases the incentive to expropriate. Formally, we obtain:

Proposition 6. The threshold level of relative technology $\tilde{\rho}\left(\beta_{G}, \delta\right)$ that enables firm investment is decreasing in the rate of depreciation: $\partial \tilde{\rho} / \partial \delta<0$.

\section{Proof. See Online Appendix.}

Thus, a higher rate of depreciation makes the incentive problem of the government worse. Without full depreciation, the government does not just expropriate current period firm output, but it can also confiscate the capital 
stock and can sell excess capital. However, since capital is less valuable under government technology than under the efficient firm technology, the stealing technology of the government becomes less effective with a slowly depreciating capital stock. With full depreciation, the government can exclusively steal efficiently transformed capital, i.e., output.

\subsection{The role of relative impatience}

This section discusses the robustness of the results with respect to the key assumption about relative impatience. For ease of exposition, other robustness checks, such as stochastic productivity, renegotiation-proof contracts, or the role of sanctions, have been moved to the Online Appendix.

The present model reveals that the optimal dynamic contract is driven by the trade-off between impatience and incentives. With homogeneous discounting, i.e., $\beta_{G}=\beta_{F}=\beta$, the frontloading motive is shut off. To make the problem interesting, assume that efficient investment, $\hat{I}$, is sustainable:

$\frac{\hat{\pi}}{1-\beta} \geq \hat{Y}+\beta v_{a u t}=\hat{v}$.

Taking the limit of Eq. (13) implies that any stationary allocation now features efficient investment, i.e., $Y_{F}^{\prime}(\bar{I})=1$. The IC-constraint does not bind and the slope of the value function is given by $\bar{\lambda}_{P K}=1$. While investment (and thus surplus) is uniquely pinned down in the long-run, the division of surplus via taxes is indeterminate. This is because in the linear region of the frontier $\left(\lambda_{P K}=1\right)$, there is no one-to-one correspondence between the slope of the value function and the promised value. With homogeneous discounting, the only surplus from the relationship is derived from (efficient) investment. Hence, as long as efficient investment is incentive compatible $(v>\hat{v})$, the dynamics of the surplus division are irrelevant. The uniqueness of the steady state transfers with relative impatience was driven by the binding IC constraint, $\bar{\tau} /\left(1-\beta_{G}\right)=\bar{Y}+\beta_{G} v_{a u t}$, which generated a steady state in the strictly concave region of the frontier. With homogeneous discounting, any combination of transfers, $\tau$, and continuation value $w \geq \hat{v}$ satisfying $\tau+\beta w \geq \hat{Y}+\beta v_{\text {aut }}$ is efficient. Therefore, global stability of investment and transfers is not ensured. In particular, any stationary transfer $\bar{\tau}<\hat{\pi}$ satisfying $\bar{\tau} /(1-\beta) \geq \hat{Y}+\beta v_{\text {aut }}$ represents a possible stationary surplus division. An arbitrarily small degree of impatience on the side of the government would remove this ambiguity.

Even with homogeneous discounting, the dynamics of transfers and investment are uniquely pinned down if $v$ is sufficiently small (in the backloading region): If $v<\beta \hat{v}$, next period's continuation value is given by $w=\beta^{-1} v$ and transfers are zero. Thus, the transfer dynamics are unique until efficient investment is reached in the next period. As a corollary, this implies that if efficient investment is never sustainable, $\hat{\pi} /(1-\beta)<\hat{Y}+\beta v_{\text {aut }}$, the corner steady state obtains and backloading is predicted until the steady state is reached.
If the firm was more impatient than the government, both the channel of impatience and incentives predict backloading. Therefore, the firm participation constraint must bind in the unique stationary allocation and the government obtains all of the surplus in the long-run, $\bar{v}=v_{\max }$.

\section{Applications}

This section aims to highlight various possible theoretical and empirical applications of my model in a nontechnical way. In Section 4.1, I discuss the implications of my analysis for industrial organization. Linkage across sectors through conglomerate structures across industries may serve as a coordination device to induce joint punishment and help sustain firm investment. I apply this idea to the specifics of the oil industry and provide a rationale for the vertical integration of oil companies. In Section 4.2, I allow for expropriation events on the equilibrium path which are generated by Markov-type discount rate shocks. The model predicts a pecking-order of expropriations determined by comparative advantage and the depreciation rate of capital. Finally, in Section 4.3, I analyze contractual agreements in the oil and automobile industry and data on expropriations and find empirical evidence consistent with the model.

\subsection{Industrial organization}

\subsubsection{Multiple sectors}

Suppose that a country consists of $J$ industrial sectors, where each sector $j$ is characterized by relative productivity $\rho_{j}$.

Definition 3 (Uncoordinated equilibrium). In an uncoordinated equilibrium, strategies in any sector $j$ can only depend on the history for the respective sector $h_{t-1, j}$.

If one restricts the analysis to the set of uncoordinated equilibria, the predictions of the basic model are applicable sector by sector. The worst possible threat point is given by return to autarky for each sector. The comparative statics of productivity (see Fig. 6) explain the cross-section of selfenforcing agreements. Specifically, in any sector $j$ with $\rho_{j}>\tilde{\rho}\left(\beta_{G}, \delta_{j}\right)$, firm investment is not sustainable.

In light of the findings of Bernheim and Whinston (1990), an ad hoc focus on uncoordinated equilibria is not without loss of generality. Their results suggest that multimarket contacts of duopolists may enhance cooperation to sustain collusive behavior.

Definition 4 (Linkage equilibrium). In a linkage equilibrium, strategies in any sector $j$ depend on the history for multiple sectors $h_{t-1,\{i\}}$ where $\{i\}$ is a subset of all sectors.

In this case, the worst possible punishment is given by the threat of autarky in all linked sectors. ${ }^{21}$ This punishment path is subgame perfect, as autarky itself is subgame perfect. Joint punishment makes expropriation less

\footnotetext{
${ }^{21}$ The associated threat becomes more effective the greater the number of participating sectors.
} 
attractive because a government cannot cherry pick its targets. As a result, technology-intensive sectors (low $\rho$ ) have a positive externality on other sectors, possibly enabling sustainable firm investment in high $\rho$ sectors. These externalities are stronger if relative productivities vary considerably across sectors. In contrast to the uncoordinated equilibrium, the relative size of sectors matters. If the mass of high-technology firms is low, linkage only provides a limited effect on the government's incentive to expropriate. $^{22}$ From this perspective, the curse of resource-rich countries is that a dominant share of their economies is exogenously concentrated in high $\rho$ sectors which reduces the effectiveness of joint punishment.

Formal or informal ties across sectors enhance the sustainability of joint punishment. In the most extreme form, firms within a conglomerate may credibly threaten to jointly punish because punishment can be effectively executed under single ownership. From a firm perspective, there exists a strong rationale for non-horizontal integration. Looser connections through alliances or semi-formal associations (such as chambers of commerce) may also help to coordinate joint punishment. ${ }^{23}$ From a government perspective, the active encouragement of coordination across sectors would serve as a commitment device.

It is unclear whether the government is better off in the uncoordinated equilibrium or in the linkage equilibrium with the maximum number of participating sectors. This depends on whether the government obtains a sufficient fraction from the greater surplus in the linkage equilibrium to compensate for the reduced threat point. Specifically, if its bargaining power is low, the government is better off in the uncoordinated equilibrium, because it can extract high transfers (albeit from a smaller number of sustainable sectors). If the government could choose which sectors to link, it cannot be worse off in a linkage equilibrium. ${ }^{24}$ The implications of the two equilibrium concepts for expropriations on the equilibrium path are discussed in the subsequent section.

\subsubsection{Exploration and extraction in the oil industry}

To capture the characteristics of the oil industry, I introduce a small variation of the analysis. ${ }^{25}$ Let $X$ now denote the cost of the exploration phase and $q$ denote the

22 The effect of relative sector size can be so extreme, that no firm investment is sustainable in a linkage equilibrium with all sectors, even though some small high-technology sectors would be sustainable on a stand-alone basis. One can eliminate this extreme outcome by allowing for subcoalitions among higher technology sectors.

${ }^{23}$ According to Greif, Milgrom, and Weingast (1994), merchant guilds served precisely this purpose in the medieval period.

24 This idea suggests a role for industrial policy. The resulting planning problem solves for the optimum organizational structure of sectors from the perspective of the government.

25 The oil industry example has some caveats. Within the special oligopoly setting of this industry, nationalization and the associated return to autarky technology may not lead to a large rent destruction for the host country: Technological incompetence of state-owned oil companies acts as a commitment device not to increase production over the agreed upon cartel quotas. This makes it possible to sustain higher prices. From this perspective, the foundation of the Organization of the Petroleum Exporting Countries (OPEC) and the wave of nationalizations in the 1970s are fundamentally connected. probability of finding oil, the probability of entering the profitable extraction phase. Moreover, let $v_{0}$ represent the initial promised value to the government, conditional on a successful exploration phase. Initial investment takes place if and only if:

$q \cdot V_{F}\left(v_{0}\right)-X>0$.

The probability of success $q$ is a measure of the firm's exploration capability. Condition (20) illustrates that successful firm investment requires simultaneously a high absolute exploration capability (high $q$ ) and a high comparative operating advantage in the extraction business (low $\rho$ ). A firm that is specialized in the exploration business (say, $q=1$ ) but only possesses a relative small comparative advantage in developing the field (say, $\rho>\tilde{\rho}$ ) cannot recover the exploration cost. ${ }^{26}$ This provides a rationale for vertical integration of exploration and extraction, even in the absence of operating synergies. $^{27}$ Consistent with this prediction, all major oil companies ("The Big Five") are engaged in both the exploration as well as the extraction business. ${ }^{28}$

\subsection{Expropriations in equilibrium}

In a non-stationary environment expropriations can occur on the equilibrium path. The deterministic model suggests that either large productivity shocks or discount rate shocks can cause expropriations. Kobrin (1980) classifies "expropriations" as nationalizations of private firms without (proper) compensation. He finds that expropriations tend to happen almost exclusively after regime changes. Since regime changes are presumably unrelated to relative productivity, I use stochastic changes in the discount factor $\beta_{G}$ (following a Markov Chain) as the identifying shock. ${ }^{29}$ Within each period, discount rate shocks occur after the firm has invested. Expropriation on the equilibrium path occurs if the discount factor jumps to a prohibitively low value. Populist leaders can be interpreted as leaders with high discount rates.

First, I will establish that the contract design outlined in the previous sections is unaffected by expropriation on the equilibrium path. For ease of exposition, assume that there are two types of regimes with $\beta_{G 1}>\beta_{G 2}$. Since we are interested in the robustness to expropriation on the equilibrium path, the economically relevant and new

${ }^{26}$ The validity of this statement hinges on the assumption that the government cannot provide sufficient up-front financing. However, even if it could, it is questionable whether large up-front financing to the firm would provide the right incentives to the firm.

27 A more general theory of vertical integration is provided by Grossman and Hart (1986).

${ }^{28}$ It is possible that a company with a high comparative advantage in the extraction business uses specialized subcontractors for the exploration phase. This assumes that firms can write legally enforceable contracts with each other. The "Big Five" is an informal expression for the following companies: ExxonMobil, Royal Dutch Shell, BP, Chevron and ConocoPhillips.

${ }^{29}$ While recent expropriations in the energy sector occurred at record price levels, suggesting that the oil price is a crucial determinant the entire history of expropriations over the past century shows no discernible pattern with respect to the oil price. For example, the earlier wave of expropriations in the 1970s occurred at relatively low oil prices 
scenario occurs when $\beta_{G 2}$ is sufficiently low such that regime 2 expropriates. Obviously, setting $\beta_{G 2}=0$ achieves this in the simplest possible way, but such an extreme assumption is not necessary. ${ }^{30}$

If $\beta_{G 2}$ is sufficiently low to cause expropriation in state 2 , we only have to consider how self-enforcing contracts with regime 1 are affected by the possibility of a regime change leading to expropriation. ${ }^{31}$ Self-enforcing contracts are only effective while the firm deals with regime $1 .^{32}$ The timing is as follows. After investment $I$ is made, regime 1 is overturned with probability $1-p$. With probability $p$, regime 1 stays in power and collects payment $\tau$ or decides to expropriate and collect the entire output $Y$. Let $V_{F}(v)$ now denote the beginning-of-period expected firm value and $v$ denote the promised value to the government in regime 1 . Using this adjustment, the selfenforcing contract with regime 1 can be characterized by the solution to the following program:

$V_{F}(v)=\max _{I, \tau, w} p\left[Y-I-\tau+\beta_{F} V_{F}(w)\right]-(1-p) I$ s.t.

\begin{tabular}{lll}
$\#$ & Constraint & Lagrange multiplier \\
\hline$(1)$ & $p\left(\tau+\beta_{G} w\right) \geq v$ & $\lambda_{P K}$ \\
$(2)$ & $\tau+\beta_{G} w \geq Y_{F}(I)+\beta_{G} v_{a u t}$ & $p \lambda_{I C}$ \\
$(3)$ & $V_{F}(w) \geq 0$ & $p \beta_{F} \lambda_{P C}$ \\
$(4)$ & $\tau \geq \tau_{\min }=0$ & $p \lambda_{\tau}$
\end{tabular}

Cash flows under the self-enforcing agreement with regime 1 are realized with probability $p$. Since expropriation always incurs upon a regime change, a negative cashflow of $-I$ obtains with probability $1-p$. Similarly, the promise-keeping constraint now accounts for the fact that the regime is only able to collect payments with probability $p$. Since the uncertainty about the regime change is resolved at the time of the expropriation decision, the probability of a regime change does not enter the incentive compatibility constraint.

Proposition 7. If expropriation occurs in state 2, the optimal dynamic contract with regime 1 is represented by the solution to the deterministic problem using $\check{Y}_{F}(I)=p Y_{F}(I)$ and $\check{\beta}_{i}=p \beta_{i}$.

Proof. Forming the Lagrangian and taking first-order conditions yields

$I: p Y_{F}^{\prime}(I)\left(1-\lambda_{I C}\right)-1=0$,

$\tau: p\left(\lambda_{P K}+\lambda_{I C}+\lambda_{\tau}-1\right)=0$

$w: p \beta_{F}\left[V_{F}^{\prime}(w)\left(1+\lambda_{P C}\right)+\frac{\beta_{G}}{\beta_{F}}\left(\lambda_{P K}+\lambda_{I C}\right)\right]=0$.

\footnotetext{
${ }^{30}$ Assuming $Y_{F}(I)=I^{\alpha}$, Proposition 1 implies that even an infinitely empowered government with discount factor $\beta_{G}<\ddot{\beta}_{G}=\rho^{(1-\alpha) / \alpha}$ would always expropriate. Therefore, a government with $\beta_{G}<\ddot{\beta}_{G}$ facing the risk of losing power cannot be incentivized to respect property rights.

${ }^{31}$ The exact level of the discount factor in state 2 is irrelevant (as long as expropriation occurs).

${ }^{32} \mathrm{I}$ implicitly require $\beta_{G 1}$ to be large enough so that regime 1 can be incentivized not to expropriate.
}

The first-order conditions with respect to $\tau$ and $w$ are identical to the deterministic setup (see Eq. (10)). The first-order condition with respect to investment accounts for the fact that the marginal product of investment is now shaded by the expropriation event. By setting $\check{Y}_{F}(I)=p Y_{F}(I)$ and $\check{\beta}_{i}=p \beta_{i}$, the deterministic solution represents the solution to the problem with expropriation risk. The optimal tax in the deterministic problem $\check{\tau}$ represents the expected tax payments, $\check{\tau}=\tau p$.

Intuitively, expropriation on the equilibrium path solely reduces the (expected) marginal product of capital. Thus, the optimal dynamic contract with the current regime 1 will only be quantitatively affected by expropriation on the equilibrium path.

Now, given the robustness of the optimal dynamic contract, expropriation upon a regime change is solely determined by the sustainability of firm investment under the new regime. As a result, in a single-sector economy expropriation takes place in all states $i$ where $\tilde{\rho}\left(\beta_{G i}\right)<\rho$. In the uncoordinated equilibrium, expropriation in private sector $j$ occurs after a regime change to government type $i$ if and only if:

$\tilde{\rho}\left(\beta_{G i}, \delta_{j}\right)<\rho_{j}$.

This leads to the following proposition:

Proposition 8. Expropriations occur according to a peckingorder, determined by relative productivity $\rho_{j}$ and the depreciation rate $\delta_{j}$. Low-technology sectors are expropriated first.

This testable proposition implies that expropriation and privatization follow a "Last-In-First-Out" principle. A sector which has just been expropriated features a higher productivity gap than the sectors expropriated in the previous periods and a lower productivity gap than the sectors which are still private. Once the type of the government changes to a more favorable regime, this sector is the first one that renders private investment feasible again. Sectors with heavy expropriation activity should have a relative productivity low enough to allow for profitable private investments in some states, but high enough to cause expropriation in other states.

\subsection{Empirical implications}

Empirical evidence on contract features between foreign firms and sovereign countries is relatively scarce. In addition, the mapping from the theory to the data is non-trivial as it requires comprehensive data from multiple sources: The model only makes predictions about the net-transfer from the firm to the government whereas real-life transfers from the firm to the government occur in multiple ways such as equity sales, dividends, taxes, or royalty payments. Likewise, governments may pay explicit transfers (subsidies), or offer tax reductions. The promised values in the theory refer to the present value of these (net) transfers and are thus not directly observable.

\subsubsection{Oil industry}

Fortunately, production sharing agreements, the most common contractual form for petroleum exploration and 
development, have been analyzed in great detail by Bindemann (1999). The analysis of production sharing agreements is promising as these contracts are outside of the general taxation system. Her data set consists of 268 production sharing agreements signed by 74 emerging market countries between 1966 and 1998. The foreign oil company assumes the entire exploration risk and is rewarded with participation in the extraction phase. Thus, bundling of exploration and extraction is an essential feature of production sharing agreements. According to my model (see Section 4.1.2), vertical integration of oil companies helps mitigate the commitment problem of the government.

Upon the start of the extraction phase, transfers to the government are mainly backloaded. ${ }^{33}$ Backloading occurs in the form of tax holidays or high initial allowances for cost oil. ${ }^{34}$ The dominance of backloading is consistent with the predictions of my model when up-front costs, $X$ (see Section 4.1.2), are large. In terms of the model, high up-front costs have the same contractual implications as a low initial capital stock (see Section 3.7). An inherent feature of production sharing agreements is a positive correlation between total transfers and output value. ${ }^{35}$ This is consistent with the results obtained in the environment with stochastic productivity shocks (see Online Appendix).

\subsubsection{Automobile industry}

There is also anecdotal evidence for the foreign direct investment of Western automobile producers in Eastern Europe. Backloading in the form of tax holidays was a common tool used by these countries (see Axarloglou and Meanor, 2006) to attract foreign direct investment. For example, when Audi invested in a production plant in Győr (Hungary), it was granted a tax holiday until 2011. Likewise, Poland granted a ten-year tax holiday in 1996 to the General Motors (GM) subsidiary Adam Opel. As many countries in Eastern Europe were competing for foreign direct investment at the same time, the firms were in a good bargaining position.

In contrast, when Volkswagen (VW) tried to acquire Ŝkoda, the third oldest automobile producer, it faced stiff competition from 23 other interested investors (with GM, Renault, BMW, and VW on the short list). In 1991, Volkswagen won the final bidding round against Renault, by paying a high up-front price for the unprofitable manufacturer: DM $1.4 \mathrm{bn}$, to be paid in three installments until $1995 .^{36}$ This accounted for $20 \%$ of foreign direct investment in the Czech Republic during that time period

\footnotetext{
${ }^{33}$ Frontloading is rarely observed, but can be implemented via signature or discovery bonuses.

${ }^{34}$ Cost oil refers to the share of oil that does not have to be taxed. Suppose cost oil is specified as $60 \%$ of production, then the firm only has to pay taxes on $40 \%$ of its output (the so-called profit oil).

35 Transfers to the government are a function of numerous parameters such as the royalty rate, tax rate, cost oil, and profit oil (see Bindemann, 1999). Profit oil represents the share of production that is taxed.

36 Though VW formally only obtained a 70\% equity stake in the firm, it secured effectively $100 \%$ of the control rights. In 2000 , VW purchased the remaining $30 \%$ from the government.
}

(see Doerr and Kessel, 1997). As predicted by the model, the intense competition by other investors allowed the cash-hungry government to obtain frontloaded payments. ${ }^{37}$ In line with the guiding theme of the model, productivity of the plants increased dramatically (by $300 \%$ ) over the first decade by replacing upper-class management with experienced Western managers, modernizing the plants, and the use of outsourcing.

\section{Conclusion}

This paper studies repeated interactions between a firm and a government in an environment where neither party can commit to a contract. The government can unilaterally seize all firm output while the technologically superior firm can refuse to invest. In this environment, weak relative technological ability of the government effectively reduces its commitment problem and makes ex ante firm investment more likely. The key result of the paper is that the government may not be better off if its incentive problem is reduced. A lower commitment problem increases investment efficiency but lowers the threat point used to extract cash flows from the firm. In the unique stationary allocation, either effect can dominate. When the government is weak, an increase in its relative ability is beneficial. However, when it becomes "too strong," firm participation can only be sustained at the cost of greater investment distortions. Firms always profit from an increase in productivity.

The model makes predictions about the dynamics of optimal self-enforcing contracts. Backloading of taxes and investment occurs if the firm is better off at the time of the initial surplus division than in the steady state. Otherwise, frontloading is optimal. The paper considers various determinants, such as the initial capital stock and competition among countries or firms, which determine the contract dynamics. When frontloading occurs, the firm acts as a sovereign debt lender. The technology advantage in production gives the firm an effective sanction mechanism without which this loan would not be feasible (see Bulow and Rogoff, 1989b).

The paper derives testable cross-sectional implications about expropriations. Expropriations should follow a pecking-order, with low-technology intensive sectors at the top. Moreover, it would be interesting to study empirically whether and how firms coordinate on joint punishment to deter the government from expropriation.

On the theory side, incorporating learning dynamics about technology into the model would be an interesting extension. My paper can already encompass the special case in which government learning is precisely offset by the improvement of firm technology, which implies a constant productivity gap. Anecdotal evidence suggests that theft of proprietary technology is an important dimension of expropriation risk. The current analysis implies that learning can only occur on the equilibrium

\footnotetext{
37 Note that the installment feature can be easily rationalized by introducing liquidity constraints on the firm side. Indeed, VW faced severe restructuring costs in the early 1990s for its Seat division in Spain.
} 
path as long as it is not "too fast." Otherwise, the firm does not invest in the first place. International automobile producers manage these learning dynamics by producing outdated models in countries where they perceive the risk of technology expropriation to be high. The future access to firm technology prevents the government from taking over current assets.

Moreover, technological transfers are sometimes not just side products or theft, but contractually arranged. For example, Siemens and Thyssen-Krupp agreed in 2000 to wide-ranging technology transfers to Chinese authorities as part of the magnetic levitation train system project "Transrapid" designed to connect the Shanghai airport to the city. Such a technological transfer from a firm to the government does not only reduce the productivity advantage (and thus increases the risk of expropriation) of this particular firm, but also of other firms in related industries. Since these externalities are only (partially) borne by a specific firm, it may be rational to transfer (some) knowledge to a government as a quid pro quo arrangement to extract higher payments (lower taxes).

Whether learning is a side-effect, contractually specified, or even strategically chosen, it seems worthwhile to incorporate endogenous learning into the present framework.

\section{Appendix A. Notation}

\begin{tabular}{|c|c|c|}
\hline Variable & Formula & Meaning \\
\hline$\alpha$ & & $\begin{array}{l}\text { Concavity parameter of the production } \\
\text { function in all figures }\end{array}$ \\
\hline$\beta_{G}$ & & Discount factor of government \\
\hline$\beta_{F}$ & & Discount factor of firm \\
\hline $\bar{I}$ & $\left(\frac{\beta_{G}}{\beta_{F}} \alpha\right)^{1 /(1-\alpha)}$ & Stationary investment level \\
\hline$\hat{I}$ & $\alpha^{1 /(1-\alpha)}$ & Efficient investment level \\
\hline $\bar{K}$ & & Stationary level of capital stock \\
\hline$\hat{K}_{i}$ & & $\begin{array}{l}\text { Optimal capital stock under } \\
\text { management of agent } i\end{array}$ \\
\hline$\lambda_{j}$ & & Lagrange multiplier of constraint $j$ \\
\hline$\lambda_{P K}^{*}$ & & $\begin{array}{l}\text { Next period's Lagrange multiplier on } \\
\text { promise-keeping constraint }\end{array}$ \\
\hline$\pi_{\text {aut }}$ & $\rho \hat{\pi}$ & Per-period profit under autarky \\
\hline$p$ & & $\begin{array}{l}\text { Probability that regime } 1 \text { remains in } \\
\text { power }\end{array}$ \\
\hline$q$ & & Probability of successful exploration \\
\hline$\rho$ & & Relative productivity of government \\
\hline$\tilde{\rho}$ & & $\begin{array}{l}\text { Maximum } \rho \text { that makes firm } \\
\text { investment feasible }\end{array}$ \\
\hline $\bar{\rho}$ & $\left(\frac{\beta_{G}}{\beta_{F}}\right)^{\alpha /(1-\alpha)} \frac{1-\frac{\alpha}{\beta_{F}}}{1-\alpha}$ & $\begin{array}{l}\text { Maximum } \rho \text { that guarantees interior } \\
\text { steady state }\end{array}$ \\
\hline$\tau$ & & Per-period transfer to the government \\
\hline$v$ & & $\begin{array}{l}\text { Current period promised value to } \\
\text { government }\end{array}$ \\
\hline$v_{\text {aut }}$ & $\frac{\pi_{a u t}}{1-\beta_{G}}$ & Discounted present value under autarky \\
\hline $\bar{v}$ & & Value to government in the steady state \\
\hline$\hat{v}$ & & $\begin{array}{l}\text { Threshold promised value that enables } \\
\text { efficient investment }\end{array}$ \\
\hline$w$ & & $\begin{array}{l}\text { Optimal continuation value to the } \\
\text { government }\end{array}$ \\
\hline$X$ & & Exploration cost \\
\hline $\bar{Y}$ & $\bar{I}^{\alpha}$ & Stationary output level \\
\hline$\hat{Y}$ & $\hat{I}^{\alpha}$ & Efficient output level \\
\hline
\end{tabular}

The formulas refer to the specific production technology $Y_{F}(I)=I^{\alpha}$.

\section{Appendix B. Proofs}

\section{B.1. Proof of Proposition 1}

The incentive constraint of the government can be simplified by substituting the expression for $v_{\text {aut }}$ into Eq. (5): $Y-\beta_{G}^{-1} I \geq \pi_{\text {aut }}$ for some $I$.

Since $\pi_{a u t}$ is independent of the firm's investment level, it is sufficient to check whether the following condition holds:

$\max _{I} Y_{F}(I)-\beta_{G}^{-1} I \geq \pi_{\text {aut }}$.

Using the maximized value of the left-hand side and the fact that $\pi_{a u t}=\rho(\hat{Y}-\hat{I})$, we obtain

$\rho \leq \max _{I} \frac{Y_{F}(I)-\beta_{G}^{-1} I}{\hat{\pi}}<1$.

The threshold level is less than one by the definition of $\hat{\pi}=\max _{I} Y_{F}(I)-I$ since $\beta_{G}^{-1}>1$.

\section{B.2. Proof of Proposition 2}

Lemma 3. In any stationary contract with positive firm investment, the government receives positive stationary transfers $(0<\bar{\tau})$ that generate a strictly higher value for the government than autarky. This implies

$\lambda_{\tau}=\bar{\lambda}_{I R}=0$.

Proof. Suppose first that $\lambda_{\tau}>0$, then the stationary contract features zero transfers from the firm to the government. This would imply a stationary value of $\bar{v}=0$ to the government, strictly less than its outside option $\bar{Y}+\beta_{G} v_{\text {aut }}$. This violates the $I C$ constraint of the government. Now suppose that the $I R$ constraint of the government was binding, then: $\bar{v}=v_{\text {aut }}$. The $P K$ and $I C$ constraint imply that $\bar{v} \geq \bar{Y}+\beta_{G} v_{a u t}$. Hence, $\bar{Y} \leq\left(1-\beta_{G}\right) v_{\text {aut }}$ and $\bar{\tau}=\left(1-\beta_{G}\right) \bar{v}=\left(1-\beta_{G}\right) v_{\text {aut }}$. Stationary firm profits are: $\bar{Y}-\bar{I}-\bar{\tau} \leq-\bar{I}<0$. This violates the participation constraint of the firm.

Lemma 4. The Lagrange multiplier $\lambda_{I C}$ is a strictly decreasing function of the promised value $v$ for all $v \in\left[v_{\min }, \hat{v}\right]$ where $\hat{v}=\hat{Y}+\beta_{G} v_{\text {aut }}$. Otherwise, $\lambda_{\text {IC }}$ equals zero.

Proof. If $\lambda_{I C}>0$, then $Y_{F}(I)+\beta_{G} v_{a u t}=v$ (by $P K$ and $I C$ ). Therefore, if $v$ increases, so must output $Y_{F}(I)$ and hence investment $I$. By the first-order condition on investment, this implies that $\lambda_{I C}$ becomes smaller. Thus, in the region where the IC constraint is binding, $\lambda_{I C}$ is strictly decreasing in $v$. If $v>\hat{Y}+\beta_{G} v_{\text {aut }}$, efficient investment is incentive compatible. Therefore, the Lagrange multiplier $\lambda_{I C}$ is zero.

The first-order condition on investment (see Eq. (10)) and Lemma 3 imply that

$\bar{\lambda}_{\text {IC }}+\bar{\lambda}_{P K}=1$.

Imposing stationarity on the first-order condition on the continuation value $\left(-V_{F}^{\prime}(w)=\bar{\lambda}_{P K}\right)$ leads to the desired 
result. Due to the Inada property of the production function, the binding IC constraint (as $\bar{\lambda}_{P K}<1$ ) implies a unique investment level and a unique promised value by Lemma 4 . Stationary transfers, which satisfy $\bar{\tau}=\left(1-\beta_{G}\right) \bar{v}$, follow from the binding IC constraint. Firm profits, $\bar{Y}-\bar{I}-\bar{\tau}$, can be simplified to: $\beta_{G} \bar{Y}-\bar{I}-\beta_{G} \pi_{a u t}$. The threshold level $\bar{\rho}$ can be obtained by setting the firm value $V_{F}(\bar{v})$ to zero:

$\bar{\rho}=\frac{\bar{Y}-\beta_{G}^{-1} \bar{I}}{\hat{\pi}}$.

\section{B.3. Proof of Lemma 2}

I define $x \equiv \lambda_{P K}^{*}-\lambda_{P K}$. If $x>0$, it follows that $\lambda_{P K}^{*}>\lambda_{P K}$ and hence $w>v$ by concavity. The transition law (see Eq. (12)) can be written as

$\lambda_{P K}+x=\frac{\beta_{G}}{\beta_{F}} \frac{\lambda_{P K}+\lambda_{I C}}{1+\lambda_{P C}}$.

Solving for $x$ in the interior region yields

$x=\frac{\beta_{G}}{\beta_{F}}\left[\lambda_{I C}-\lambda_{P K}\left(\frac{\beta_{F}}{\beta_{G}}-1\right)\right]$.

At the steady state, $x=0$. For $v<\bar{v}, x$ is strictly positive, because $\lambda_{I C}$ is a strictly decreasing function of $v$ by Lemma 4 and $\lambda_{P K}$ is a strictly increasing function of $v$ which implies for all $v<\bar{v}$ that $\lambda_{I C}>\bar{\lambda}_{I C}$ and $\lambda_{P K}<\bar{\lambda}_{P K}$. The strict monotonicity follows from the binding IC constraint at the steady state. Therefore, if $v<\bar{v}$, continuation values are increasing $w>v$. Analogous arguments yield that if $v>\bar{v}$, continuation values must be decreasing. If the stationary contract is a corner contract, then only the region to the left is relevant.

\section{B.4. Proof of Proposition 4}

As long as $v \neq v_{\max }$, the PC constraint does not bind, which implies for the transition law:

$\lambda_{P K}^{*}=\frac{\beta_{G}}{\beta_{F}}\left(\lambda_{P K}+\lambda_{I C}\right)$.

Using the first-order condition on the tax rate: $\lambda_{P K}+\lambda_{\text {IC }}=1-\lambda_{\tau}$, we obtain

$\lambda_{P K}^{*} \frac{\beta_{F}}{\beta_{G}}=1-\lambda_{\tau}$.

Part (a) Suppose the current value is lower than the steady state $(v<\bar{v})$, but the continuation value satisfies $w=\bar{v}$, such that $\lambda_{P K}^{*}=\bar{\lambda}_{P K}=\beta_{G} / \beta_{F}$. Then, the left-hand side of Eq. (B.10) equals one, which implies: $\lambda_{\tau}=0$. The promise-keeping constraint $v=\tau+\beta_{G} \bar{v}$ yields the optimal transfer payment $\tau$. If $w<\bar{v}$ (i.e., $\left(v<\beta_{G} \bar{v}\right)$, it follows that $\lambda_{P K}^{*}<\bar{\lambda}_{P K}=\beta_{G} / \beta_{F}$ (by strict concavity of the value function to the left of the steady state). Hence, the left-hand side of Eq. (B.10) is less than one. This implies that the constraint on the minimum tax binds: $\lambda_{\tau}>0$. Therefore, the optimal tax is $\tau=\tau_{\min }=0$.

Part (b) The proof strategy is analogous to part (a). Since there is no liquidity constraint on the side of the firm, the steady state is immediately reached.
As long as the IC constraint binds, investment is given by the $P K$ and $I C$ constraints.

$I(v)=Y_{F}^{-1}\left(v-\beta_{G} v_{a u t}\right)$.

If the IC constraint does not bind, then investment is given by the efficient level $I(v)=\hat{I}$. Since $Y_{F}^{-1}\left(v-\beta_{G} v_{a u t}\right)$ is continuous, increasing in $v$, and unbounded, there exists a critical value of $\hat{v}=\hat{Y}+\beta_{G} v_{a u t}>\bar{v}$ such that

$I(v)= \begin{cases}Y_{F}^{-1}\left(v-\beta_{G} v_{a u t}\right) & \text { for } v<\hat{v}, \\ \hat{I} & \text { for } v \geq \hat{v} .\end{cases}$

\section{Appendix C. Supplementary data}

Supplementary data associated with this article can be found in the online version at doi:10.1016/j.jfineco.2011. 08.010 .

\section{References}

Abreu, D., 1988. On the theory of infinitely repeated games with discounting. Econometrica 56, 383-396.

Acemoglu, D., Golosov, M., Tsyvinski, A., 2008. Political economy of mechanisms. Econometrica 76, 619-641.

Acemoglu, D., Golosov, M., Tsyvinski, A., 2010. Dynamic Mirrlees taxation under political economy constraints. Review of Economic Studies 77, 841-881.

Acemoglu, D., Johnson, S., Robinson, J.A., 2001. The colonial origins of comparative development: an empirical investigation. American Economic Review 91, 1369-1401.

Aguiar, M., Amador, M., Gopinath, G., 2009. Investment cycles and sovereign debt overhang. Review of Economic Studies 76, 1-31.

Albuquerque, R., Hopenhayn, H.A., 2004. Optimal lending contracts and firm dynamics. Review of Economic Studies 71, 285-315.

Amador, M., 2004. A political model of sovereign debt repayment. Unpublished working paper, Stanford University.

Axarloglou, K., Meanor, F.G., 2006. Taxation and ownership structure in supplying foreign markets. Eastern Economic Journal 32, 685-698.

Becker, G.S., Stigler, G.J., 1974. Law enforcement, malfeasance, and compensation of enforcers. The Journal of Legal Studies 3, 1-18.

Bernheim, B.D., Whinston, M.D., 1990. Multimarket contact and collusive behavior. RAND Journal of Economics 21, 1-26.

Biais, B., Perotti, E., 2002. Machiavellian privatization. American Economic Review 92, 240-258.

Bindemann, K., 1999. Production-sharing agreements: an economic analysis. Unpublished working paper, Oxford Institute for Energy Studies.

Bridgman, Benjamin, Gomes, Victor, Teixeira, Arilton, 2011. Threatening to increase productivity: evidence from Brazil's oil industry. World Development 39 (8), 1372-1385.

Bulow, J., Rogoff, K., 1989a. A constant recontracting model of sovereign debt. Journal of Political Economy 97, 155-178.

Bulow, J., Rogoff, K., 1989b. Sovereign debt: Is to forgive to forget? American Economic Review 79, 43-50

DeMarzo, P.M., Fishman, M.J., 2007. Optimal long-term financial contracting. Review of Financial Studies 20, 2079-2128.

DeMarzo, P.M., Fishman, M.J., He, Z., Wang, N. Dynamic agency and the $\mathrm{q}$ theory of investment. Journal of Finance, forthcoming.

Doerr, G., Kessel, T., 1997. Das Restrukturierungsmodell Skoda-Volkswagen - Ergebnis aus Transfer und Transformation. Unpublished working paper, Wissenschaftzentrum Berlin für Sozialforschung.

Eaton, J., Gersovitz, M., 1981. Debt with potential repudiation: theoretical and empirical analysis. Review of Economic Studies 48, 289-309.

Greif, A., Milgrom, P., Weingast, B.R., 1994. Coordination, commitment, and enforcement: the case of the merchant guild. Journal of Political Economy 102, 745-776.

Grossman, S.J., Hart, O.D., 1986. The costs and benefits of ownership: a theory of vertical and lateral integration. Journal of Political Economy 94, 691-719.

Harris, M., Holmstrom, B., 1982. A theory of wage dynamics. Review of Economic Studies 49, 315-333. 
Hart, O., Moore, J., 1994. A theory of debt based on the inalienability of human capital. The Quarterly Journal of Economics 109, 841-879.

Hart, O., Moore, J., 1998. Default and renegotiation: a dynamic model of debt. The Quarterly Journal of Economics 113, 1-41.

Hellwig, C., Lorenzoni, G., 2009. Bubbles and self-enforcing debt. Econometrica 77, 1137-1164.

Kikeri, S., Nellis, J., Shirley, M., 1992. Privatization: The Lessons of Experience. World Bank, Washington, DC.

Kobrin, S.J., 1980. Foreign enterprise and forced divestment in LDCs. International Organization 34, 65-88.

Kovrijnykh, N., 2009. Debt contracts with partial commitment. Unpublished working paper, Arizona State University.

La Porta, R., Lopez-de-Silanes, F., Shleifer, A., Vishny, R.W., 1998. Law and finance. Journal of Political Economy 106, 1113-1155.
Lehrer, E., Pauzner, A., 1999. Repeated games with differential time preferences. Econometrica 67, 393-412.

Levin, J., 2003. Relational incentive contracts. American Economic Review 93, 835-857.

Li, Q., 2009. Democracy, autocracy, and expropriation of foreign direct investment. Comparative Political Studies 42, 1098-1127.

Ljungqvist, L., Sargent, T.J., 2004. Recursive Macroeconomic Theory, second ed. World Bank, Washington, DC.

Rajan, R.G., Zingales, L., 2003. Saving Capitalism from the Capitalists. Crown Business, New York, NY.

Ray, D., 2002. The time structure of self-enforcing agreements. Econometrica 70, 547-582.

Thomas, J., Worrall, T., 1994. Foreign direct investment and the risk of expropriation. Review of Economic Studies 61, 81-108. 